\title{
Ciencias del Comportamiento
}

Citación: Gómez-Gutiérrez A, Portilla JG. Francisco José de Caldas: ¿avatar de Humboldt? Reflexiones en torno a cinco cartas anónimas publicadas en el Diario Político de Santafé de Bogotá en 1810. Rev. Acad. Colomb. Cienc. Ex. Fis. Nat. 45(175):387-404, abril-junio de 2021. doi: https://doi.org/10.18257/ raccefyn. 1449

Editor: Elizabeth Castañeda

\section{*Correspondencia:}

José Gregorio Portilla Barbosa;

jgportillab@unal.edu.co

Recibido: 7 de abril de 2021

Aceptado: 18 de mayo de 2021

Publicado: 17 de junio de 2021

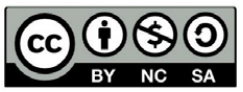

Este artículo está bajo una licencia de Creative Commons ReconocimientoNoComercial-Compartir Igual 4.0 Internacional
Ensayo

\section{Francisco José de Caldas: ¿avatar de Humboldt? Reflexiones en torno a cinco cartas anónimas publicadas en el Diario Político de Santafé de Bogotá en 1810}

\author{
Francisco José de Caldas: Humboldt's avatar? Reflections \\ on five anonymous letters published in the Diario Político de \\ Santafé de Bogotá in 1810 \\ (D) Alberto Gómez-Gutiérrez ${ }^{1}$, (D) José Gregorio Portilla ${ }^{2, *}$ \\ ${ }^{1}$ Instituto de Genética Humana, Facultad de Medicina, Pontificia Universidad Javeriana, Bogotá, Colombia \\ ${ }^{2}$ Observatorio Astronómico Nacional, Facultad de Ciencias, Universidad Nacional de Colombia
}

\section{Resumen}

Las cinco cartas redactadas por un viajero europeo anónimo que habría recorrido el virreinato de la Nueva Granada en los años 1803 y 1804, y que fueron luego publicadas en el Diario Político de Santafé de Bogotá en el curso del segundo semestre de 1810, proporcionan información valiosa sobre diversos aspectos de la vida colonial en Santafé y sus alrededores. Estas cartas permiten poner en evidencia ciertas inconsistencias y anacronismos que revelan la intención fundamental de publicitar una situación favorable para los habitantes de Santafé de Bogotá tras los sucesos que iniciaron el interregno previo a su independencia de la corona española. La identidad del autor de estas cinco cartas se aproxima excesivamente a la Alexander von Humboldt, quien había circulado por los mismos lugares dos años y medio antes, en 1801. En ausencia de un registro histórico que permita sustentar el paso del viajero anónimo identificado solo con las iniciales "L. R.", se sugiere que este hipotético europeo pudo ser, en realidad, una invención de uno de los editores neogranadinos de este diario, probablemente Francisco José de Caldas.

Palabras Clave: Francisco José de Caldas; Alexander von Humboldt; Diario Político de Santafé de Bogotá; Siglo XIX; Nueva Granada.

\begin{abstract}
Five letters written by an anonymous European who appear to have travelled through the viceroyalty of New Granada between 1803 and 1804, and then published in the Diario Politico de Santafé de Bogotá in 1810, provide valuable information on various aspects of the colonial life in Santafé and its surroundings. These letters include several inconsistencies and anachronisms and reveal an evident intention to support a favorable situation of Santafé de Bogotá after the events that opened an interregnum that preceded its independence from the Spanish crown. The identity of the author of these five letters is excessively similar to that of Alexander von Humboldt, who had circulated through the same regions two and a half years earlier, in 1801. In the absence of any historical record supporting visits to these regions by the anonymous traveler, who identifies himself solely with the initials "L. R.", we suggest that this hypothetical European was invented by one of the NeoGranadian editors of this journal, most probably by Francisco José de Caldas.
\end{abstract}

Key words: Francisco José de Caldas; Alexander von Humboldt; Diario Político de Santafé de Bogotá; 19th century; New Granada.

\section{Introducción}

La Constitución Feliz, el Aviso al Público y el Diario Político de Santafé de Bogotá $(D P S B)$, fueron publicaciones de carácter semioficial surgidas pocas semanas después de la asonada del 20 de julio de 1810. Su propósito era el de servir de órganos de difusión 
de la Junta Suprema del Nuevo Reino de Granada, esto es, del nuevo gobierno que se venía de instaurar. La primera de estas gacetas apareció el 17 de agosto de 1810, bajo la responsabilidad del fundador del periodismo neogranadino, Manuel del Socorro Rodríguez (1758-1819). Esta publicación solo llegó a tener una entrega (Martínez Delgado \& Ortiz, 1960; Rojas, 2013), y se ha sugerido que se suspendió por carecer del suficiente fervor patriótico que los tiempos exigían. El Aviso al Público, por su parte, estuvo activo entre el 29 de septiembre de 1810 y el 16 de febrero de 1811 , llegó a tener 21 números, y su edición y la casi totalidad de su financiación estuvo a cargo de fray Diego Francisco Padilla (1751-1829), sacerdote agustino cuya presencia en la Junta Suprema en calidad de vocal reflejaba su marcado interés por los asuntos políticos (Campos y Fernández de Sevilla, 2011). Finalmente, el DPSB operó entre el 27 de agosto de 1810 y el 1 de febrero de 1811 ; emitió 46 números ( 6 de ellos con suplemento) y tuvo por editores a José Joaquín Camacho (1766-1816) -también vocal de la Junta Suprema- y a Francisco José de Caldas (17681816), ambos abogados rosaristas y participantes activos en el levantamiento criollo que condujo finalmente a la deposición del virrey Antonio José Amar y Borbón (1742-1826). Caldas, en particular, fue un naturalista validado por Alexander von Humboldt (17691859) y contaba ya con una sólida experiencia con la pluma a través de la edición del Semanario del Nuevo Reyno de Granada (SNRG), la primera publicación de clara índole científica y cultural del virreinato. Así, el periodista esencialmente científico daba ahora espacio al periodista político amateur.

El propósito fundamental y explícito del $D P S B$ era la "propaganda política y la publicación de los actos de gobierno" (Martínez Delgado \& Ortiz, [1960] 2018). De esta manera, era evidente su intención de inflamar el espíritu patriótico en la población, y orientar y concientizar a los criollos ante el nuevo panorama social, político y económico que imponían las circunstancias. Si bien en un inicio, y por más de la mitad de los números, operó como memoria histórica de los eventos que se desarrollaron a finales del mes de julio y de agosto en Santafé -solo interrumpida brevemente por la narración de eventos violentos ocurridos el 2 de agosto en Quito-, el DPSB registra un número alto de noticias de sucesos ocurridos en otras poblaciones del virreinato (tales como conformaciones de Juntas), de otros virreinatos (Nueva España, Río de la Plata) o de la misma península ibérica, algunos relatando acontecimientos de naturaleza bélica. De igual forma, son numerosos los registros de bandos, arengas, proclamas y actas, así como avisos al público de diversa índole, resultados de juicios y nombramientos en cargos civiles y militares. En algunos números aparecen "lecciones" o "principios" de naturaleza cívica, moral, política y económica que, a juicio de sus autores, debían caracterizar a un ciudadano o a una nación para poder prosperar.

El DPSB incluye también un número no despreciable de cartas emanadas como resultado de un pronunciamiento de una Junta en particular, o como comunicación entre notables figuras políticas y religiosas. En algunos casos se reproducen cartas tomadas de otros periódicos (como por ejemplo la Gaceta de Caracas). En la gran mayoría de esas cartas se identifica claramente al autor aun cuando hay varias de ellas en las que la identificación del redactor es desconocida, sin pasar de ser un anónimo común y corriente. Sin embargo, al menos en el caso que se comentará a continuación, la identidad del autor anónimo no es común, ni corriente: es problemática. El primer tipo de anonimato lo constituye, por ejemplo, una "relación anónima" que apareció en los números 7 y 8 , dirigida al virrey Amar y Borbón, en la que se relatan algunos hechos violentos acaecidos en Quito. El segundo tipo de anonimato, que constituye el motivo de la presente reflexión, corresponde a cinco cartas del viajero L. R. (sic) redactadas en Santafé de Bogotá o sus alrededores, entre el 3 de diciembre de 1803 y el 19 de febrero de 1804. Estas fueron publicadas por entregas a lo largo de seis números del DPSB en 1810 (Tabla 1). Las cartas son relevantes por su naturaleza cultural y científica, y denotan una clara pericia intelectual de parte de su autor. No obstante, son varias las razones para sostener que la identidad del redactor de dichas cartas es incierta, más allá de solo haber sido firmadas con un "L. R."; la primera de ellas es que la visita de este eventual viajero y su misterioso acompañante, 
Tabla 1. Cartas del viajero L. R. publicadas en el Diario Politico de Santafé de Bogotá

\begin{tabular}{llcl}
\hline Carta & Fecha & $\begin{array}{c}\text { No. del } \\
\text { DPSB }\end{array}$ & Fecha de publicación \\
\hline 1 & 03 de diciembre de 1803 & 16 & 16 de octubre de 1810 \\
\hline 2 & 19 de diciembre de 1803 & 17 & 19 de octubre de 1810 \\
\hline 3 & 03 de enero de 1804 & 18 & 23 de octubre de 1810 \\
\hline 3 (cont.) & 03 de enero de 1804 & 19 & 26 de octubre de 1810 \\
\hline 4 & 08 de febrero de 1804 & 21 & 2 de noviembre de 1810 \\
\hline 5 & 19 de febrero de 1804 & 27 & 27 de noviembre de 1810 \\
\hline
\end{tabular}

ambos aparentemente europeos, solo dispone, hasta la fecha, de su registro en el DPSB. La evidente autoridad de Caldas y Camacho en su función editorial podría explicar esta aceptación (o desatención) histórica, dado que, desde finales del siglo XIX, ningún historiador ha puesto en tela de juicio la identidad o, incluso, la existencia de esta dupla de viajeros en el Nuevo Reino de Granada (Ibañez, [1893] 1951; Tisnés, 1956; Martínez Delgado \& Ortiz, 1960; Hernández de Alba \& Carrasquilla, 1977; Del Molino, 2017).

De modo que la motivación de nuestro análisis (y de nuestra hipótesis resultante) consiste en exponer los argumentos por los cuales consideramos discutible la identidad del autor de esas misivas. En consecuencia, buscamos ofrecer razonamientos que permitan identificar al verdadero redactor de estas cartas que consideraremos, operativamente, como pseudo-anónimas, transcribiendo su contenido integral anotado, antes de plantear las razones por las cuales se pone en duda la existencia del viajero L. R., así como los elementos que nos permiten sugerir la identidad de su verdadero autor.

\section{Las cinco cartas de L. R.}

Tal y como se mencionó en la introducción, los documentos de estudio son un total de 5 cartas atribuidas a un viajero venido de Europa, cuya identidad solo se conoce por las letras L. R. (presumiblemente las iniciales de su nombre y apellido), quien habría circulado por Santafé y sus alrededores entre los meses de noviembre de $1803 \mathrm{y}$, al menos, febrero de 1804. En la tabla 1 se inscribe el número de cada carta enfrentado a la fecha de su redacción, al número correspondiente del Diario Político de Santafé de Bogotá en el que fue publicada y a la fecha de su publicación.

A continuación se transcriben las cinco cartas referidas en las que se ha actualizado la ortografía de cada texto, con excepción de algunos términos significativos que se califican con un (sic) inmediato, así como del título que le fue asignado en cada número del $D P S B$ como "Cartas del Viagero L. R.", en el que el término "Viagero" aparece a veces con tilde en la e.

\section{Carta n. ${ }^{\circ} 1$}

Hemos creído oportuno dar a luz las siguientes Cartas del Viagero L. $R$. por darse a conocer en ellas las ventajas que reúne la Capital de Santafé.

Santafé de Bogotá, 3 de diciembre 1803

Mi amigo,

El día 20 del mes anterior entramos en la llanura de Santafé. No te puedo ponderar la sensación que me causó un golpe tan hermoso, después de haber atravesado las malezas del río Magdalena, y el resto de mal camino por tierra desde Honda hasta Facatativá, de que te hablé en mi carta anterior. ${ }^{1}$ Desde este último sitio se muda la escena, y de repente se presenta a la vista un plano inmenso, rodeado de montañas, que forman el más bello anfiteatro.

\footnotetext{
${ }^{1}$ Esta carta no se conoce.
} 
Multitud de pueblos sembrados por toda esta llanura, hacen grupos vistosos, que varían agradablemente la plataforma; en la que también se registran casas de campo bien situadas, algunas de regular construcción, manteniéndose por todas partes rebaños numerosos. A uno y a otro lado del camino se ven tropas de caballos, que retozan alegremente; se oyen los mugidos de las vacas y balar las ovejas; el viajero cree verse transportado a las llanuras de Egipto, de que nos han dejado tan bellas descripciones los antiguos. Tiene esta explanada 16 leguas de largo y cerca de 7 de ancho, no conociéndose a la vista su inclinación que se aumenta hacia el Norte. La atraviesa el río de Bogotá, que después de haber fecundado las tierras por donde pasa con inundaciones periódicas, va a precipitarse en Tequendama, donde forma la más alta y bella cascada del mundo, cuya caída según varias medidas que se han hecho es de más de 300 varas (sic) ${ }^{2}$ castellanas.

La fecundidad de estos campos es maravillosa; se cubren dos veces al año de sementeras, que contribuyen para el sustento y regalo de sus moradores. Pocas cosas echan aquí [de] menos los europeos. Vegetan perfectamente las plantas de las zonas templadas; el trigo, las coles, las lechugas, cardos, alcachofas, y demás hortalizas; manzanos, duraznos, cerezos, ciruelos, etc. Todo esto encanta, después de un tan largo y molesto camino en que no se ven sino plantas del trópico. Los prados naturales mantienen casi todo el año su verdor; abundan el poleo, salvias, y otras plantas olorosas; y están matizados los campos con ranúnculos y otras muchas flores de hermoso olor, entre las que sobresale una especie Hipochaeris, ${ }^{3}$ que en el país llaman chicoria, cuyas flores amarillas, esparcidas por el campo, forman un cielo verde con estrellas de oro. ¿No te acuerdas haber leído en los Mundos de Fontenelle ${ }^{4}$ la pintura de este cielo que tenemos aquí a nuestros pies?

La capital se alcanza a ver desde muy lejos. En sus cercanías se ha construido una larga calzada de piedra para facilitar los transportes, que sin este beneficio serían muy difíciles por la inundación de los campos en tiempo de aguas. Esta calzada o camellón sirve también para los paseos de a caballo, y si se continuase por todo el llano sería comparable a las vías romanas.

Santafé está fundada al pie de dos grandes cerros que vierten aguas cristalinas y abundantes, que corren por todas las calles y conducen a la limpieza de la ciudad, que no se halla muy bien atendida, a pesar de estas grandes proporciones, y de dos ríos que corren por medio de ella, y que bajo otro gobierno podrían contribuir más al placer y a la salubridad. Casi todas las calles son derechas. Los empedrados se hallan en muy mal estado sin embargo que abundan los alrededores de piedra pequeña y sin ángulos, la más a propósito para los pavimentos. También se saca de las entrañas de los cerros y escarpes de los ríos un excelente gres, que sirve para los enlozados que se van construyendo en el glacis de las casas.

La población constará de 35.000. Los ciudadanos están dotados de genio, y se observa, en casi todos, un deseo insaciable de saber. A mi compañero y a mí nos rodean continuamente, queriendo imponerse de todo, de suerte que, si nos estableciésemos en este lugar, dentro de poco tiempo tendríamos tantos discípulos como se dice haber tenido Mr. Cujas. ${ }^{5} \mathrm{Me} \mathrm{lisonjeo}$ que les enseñaríamos cosas menos desagradables y más útiles que las que enseñaba aquel viejo jurisconsulto. Hay hombres bastante instruidos, reina, en todos, un gusto delicado, expresión fina, y si hubiera cultivo podría ser esto un París. Pero el Gobierno favorece poco las ciencias, y mucho menos las artes, que perjudicarían al sistema colonial.

Se nos han hecho muchos obsequios, y desde nuestra llegada apenas he tenido este corto rato para escribirte precipitadamente. Después te daré razón más extensa de todo lo que me ocurra, y dispensarás por ahora la brevedad con que te saluda tu afectísimo amigo.

${ }^{2}$ Caldas había reportado 219 varas y Humboldt 220 varas castellanas para esta cascada. Véase: Mantilla, Ochoa y Martínez (2016).

${ }^{3}$ Se refiere al género Hypochaeris, planta asterácea originaria de Europa e introducida América, cuya especie $H$. radicata se conoce como achicoria o diente de león.

${ }^{4}$ La obra Conversaciones acerca de la pluralidad de los mundos traducida al español del original Entretiens sur la pluralité des mondes (1686) del escritor francés Bernard Le Bouyer de Fontenelle (1657-1757) intentó socializar el modelo heliocéntrico propuesto por Nicolás Copérnico (14731543) y defendido frente a la Inquisición por Galileo Galilei (1564-1642).

${ }^{5}$ Jacques Cujas (1522-1590), jurisconsulto francés del siglo XVI, referente del humanismo jurídico y autor de varias obras compiladas en 1722 bajo el título de Opera Omnia en 10 tomos. 


\section{Carta.$^{\circ} 2$}

Carta segunda escrita por el Viagéro L. R.

Santafé de Bogotá, diciembre 19 de 1803

Mi pensado amigo,

Como hace algunos días que habito este país, te puedo ya hablar de su temperamento, con que me he familiarizado. Su invariabilidad contribuye a que los extranjeros nos acostumbremos fácilmente a la impresión. Si tornamos las cosas en grande, esta temperatura equivale a la de París, porque sumando los grados de calor que se sufren aquí en el espacio de un año con indicaciones uniformes, son casi iguales a los que allá se experimentan en variaciones estacionales.

En Santafé el termómetro por lo regular señala 12 a 14 grados. Te confieso que esta uniformidad es ventajosa para las gentes de letras, porque el espíritu puede permanecer aquí en una acción casi continua, sin que ni el demasiado calor ni el excesivo frío impidan el uso de las potencias. Si las ciencias llegasen a emigrar a la América, como algunos han pronosticado, establecerían aquí su imperio. Tal vez los sucesos actuales de Europa preparan esta revolución. Yo me alegraría [de] que los hados fuesen en adelante menos injustos con esta bella porción del Universo, y que se aprovechasen las disposiciones que no puedo menos que admirar en estos hijos de la naturaleza, que lejos de recibir algún fomento, tiene que luchar continuamente contra un gobierno que trabaja incesantemente en su degradación.

Por un aborto (sic) extraordinario se ha construido casi en el centro de la ciudad un bello Observatorio, que será el segundo que se levanta en el Nuevo Mundo, después del que se conoce en Filadelfia. ${ }^{6}$ Llegará el día en que los Herschels, ${ }^{7}$ la Land (sic), ${ }^{8}$ y otros excelentes Astrónomos ocupen este edificio, que hará siempre honor al célebre Mutis, que lo ha construido. Está proveído de buenos instrumentos; un cuarto de círculo, sextantes, teodolitos, telescopios, el péndulo de Graham, que trajeron a Quito nuestros académicos en el año de 1735, y otras máquinas que jamás soñé hallar en estas distantes regiones. El pasaje de Venus por el disco del Sol, para que nos han citado los astrónomos, será observado desde este punto. ${ }^{9}$ No carece esta capital de hombres capaces de hacer esta delicada observación, y de corresponderse con los observadores europeos. La astronomía no puede menos que hacer grandes progresos en un país donde se registran ambos hemisferios. Está sin duda reservado a los sabios de América darnos una descripción completa de las constelaciones australes.

Otro Viagéro os diría muchas cosas de las Iglesias, conventos, hospicios, etc., pero yo debo pasar todo esto en blanco, hablando con un hombre que debe haber calculado el estado de estos establecimientos bajo la mano española que los dirige. No quiero cansarte más, y voy a despedirme para un paseo a que se me ha convidado, y a que seguiremos el día de mañana. Voy gustoso porque todo es camino llano, y no hay asperezas que vencer, lo que es muy raro en los países ecuatoriales. A poca costa se podrían poner aquí caminos que se anduviesen en coche para comunicarse entre sí todos los lugares de la explanada. Adiós: después te daré razón de mi viaje.

${ }^{6}$ Del Observatorio de Filadelfia habla el autor de las Cartas del Cultivador Americano [Nota a pie de página en el original]. Para mayor información sobre el desarrollo de la astronomía en Filadelfia, véase Bell (1964), en: https://www.jstor.org/stable/985991?seq=1. La obra citada podría corresponder a las Letters from an American farmer. Describing certain privincial situations, manners, and customs, not generally known; and conveying some idea of the late and present interior circumstances of the British colonies of North America, es decir, John Hector St John, quien había nacido en Normandía con el nombre de Michel Guillaume Jean de Crèvecoeur (1735-1813), obra publicada en Londres en 1782. Vease: https://babel.hathitrust.org/cgi/pt?id=aeu.ark:/13960/t0gt5z84d\&view=1up\&seq=6. ${ }^{7}$ Se refiere, probablemente en plural mayestático, a William Herschel (1738-1822), músico y astrónomo británico, descubridor del planeta Urano. Su hijo, John Herschel (1792-1871), fundador y presidente de la Royal Astronomical Society, solo figuró a partir de la segunda década del siglo XIX. ${ }^{8}$ Joseph Jérôme Lefrançois de Lalande (1732-1807), astrónomo francés, autor de la obra en 4 volúmenes titulada Traité d'astronomie (1771-1781).

${ }^{9}$ Este es un comentario curioso, ya que para la fecha se habían sucedido dos tránsitos de Venus: en 1761 y 1769 . Los siguientes se esperaban para 1874 y 1882. 


\section{Carta $n^{\circ} 3$}

Carta tercera escrita por el Viagéro L. R.

Zipaquirá, enero 3 de 1804

Amigo,

Rodeado como estoy de los ilustres ciudadanos de Santafé que me han acompañado a este sitio, y que me honran con su amistad, no puedo escribirte con la extensión que quisiera sobre lo físico de estos países. Nos hallamos en Zipaquirá, uno de los puntos más interesantes del reino. Este lugar está situado 5 leguas al Norte de la capital, su población será de 4000 almas, su elevación sobre el mar 1440 toesas. Con las sales que se fabrican en este sitio y en los pueblos vecinos de Tausa y Enemocón (sic), se proveen casi todas las provincias interiores de la Nueva Granada. La riqueza de estas minas es muy considerable, produciendo la sal gema 92 centésimos de sal cocida o consumptible (sic). El total de las sales que se fabrican annualmente (sic) en dichos tres laboratorios pasa de 200.000 arrobas. Su producto líquido, que asciende a más de 50.000 pesos, está consagrado a los hospicios, vecinos, blancos, indios y el resto para, el tesoro real.

Hace dos semanas que estamos aquí y en este espacio he hecho varias visitas al pie de la montaña donde están las oficinas del rey. Todo se ejecuta del modo más dispendioso. En lugar de hacer galerías subterráneas, y manantiales artificiales que subsistan perennemente, se hacen cortes abiertos, que se multiplican todos los días, cubriendo con los escombros los sitios donde después se deben hacer nuevas explotaciones. Esta economía la aprendieron los españoles de los indios bárbaros, que trabajaban estos minerales mucho tiempo antes de la conquista.

La sal gema se encuentra en muchos parajes bajo una capa de yeso que aumenta la riqueza del país, transportándose este mineral a Santafé donde se emplea en obras de arquitectura. Los vasos coctorios (sic) de la sal se hacen de barro y se rompen pasada la operación. En las tres técnicas referidas, se consumen annualmente (sic) 37.000 cascos que importan 4000 pesos. En Tirol y otros establecimientos de Alemania, se cocinan en una sola caldera de plomo las 200.000 arrobas de sal, que se fabrican en dichos tres lugares Los Indios de Tocancipá y Gachancipá se aprovechan de este desperdicio, construyendo éstas ollas de cocción de una excelente arcilla, que abunda en sus territorios.

La leña que se destruye en dichos establecimientos es infinita. En Zipaquirá solo se queman todos los años 1.600 .000 pies cúbicos de leña, que importan a 25.000 pesos. ${ }^{10}$ Esta enorme pérdida de combustible proviene de la multitud de vasos coctorios, mala construcción de hornos, y de la poca concentración de las aguas saladas que se evaporan, y que se prohíben enriquecer con la sal gema en los trabajos de Enemocón. Si estos establecimientos se pusieran en pie regular de economía, producirían riquezas inmensas al Estado. El Barón de Humboldt, que visitó estas salinas en 1801, escribió una excelente Memoria, en que prescriben reglas para dirigir la evaporación de las sales. Hasta ahora no se han sabido aprovechar los trabajos de este grande hombre. El gobierno debe interesarse en adelantar y perfeccionar la explotación y fábrica de este ramo de industria, que hace uno de los fondos principales del erario, y que liga las provincias a la capital. El consumo de la sal debe ir en aumento al paso que se adelante la población, debiéndose cuidar de la conservación de estos minerales preciosos, que se destruirán si no se establecen las fuentes artificiales, como se han destruido en Europa otros minerales de igual riqueza.

\section{Carta n. 3 (continuación)}

\section{Continuación de la tercera carta del Viagero L. R.}

Se encuentra la sal gema en otros puntos hacia la parte septentrional del reino, como es en San Juan de Sesquilé, en Chámesa de los Llanos de Casanare, en Pinsayma ${ }^{11}$ cerca de

\footnotetext{
${ }^{10}$ Estas cifras coinciden exactamente con lo reportado por Humboldt en 1801. Para consultar la versión integral comentada de la Memoria del prusiano, véase Gómez Gutiérrez (2018, II, 39-61)

${ }^{11}$ Esta localidad queda a mitad de camino entre Zipaquirá y Honda en línea recta, cerca de la población de Nocaima en el departamento de Cundinamarca.
} 
Honda, en Chita jurisdicción de Tunja, en San Andrés de la Provincia de Pamplona, en cuyos parajes no se hacen extracciones considerables a excepción de Chita y Chámesa, cuyas salinas se trabajan por cuenta del Rey.

El ramo de las sales en Zipaquirá y lugares inmediatos bien dirigido podría producir al erario una renta de más de cien mil pesos, no pudiéndose pasar las gentes sin este objeto de primera necesidad, cuya falta se suple en algunos países del reino con la ceniza de ciertas plantas, que se emplea para condimentar los alimentos, lo que observé en algunos pueblos del Orinoco, y se dice acontecer lo mismo con la provincia de Antioquia. En las naciones civilizadas de Europa perjudica al consumo de la sal el uso del azúcar que se emplea en los alimentos en lugar de aquella, siendo más agradable al gusto; pero tal vez menos provechosa a la salud por su glutinosidad; es verdad que el azúcar sería mucho más costoso si se emplease en lugar de la sal, a la que solo se podría sustituir para halagar el gusto. En estos lugares se gasta mucha profusión en los dulces, y te admirarías si te hallaras presente en los espléndidos convites con que se nos obsequia y en que hemos visto muchas composiciones gastronómicas que lograrían aprecio en la culta Europa.

Yo soy ingenuo, y como ya te he dicho en otras cartas, no puedo menos que confesar las grandes ventajas que aquí se gozan, y que quisiera dividir contigo. A lo menos te libertarías del fracaso de la guerra que turba ese emisferio (sic). Aquí reina una paz profunda, y las noticias de Europa circulan entre muy pocos. Creo que por estas bellas circunstancias viviría contento en este país ameno; pero la mitad de mi ser está lejos de mí, y no puedo vivir gustoso sin mi caro amigo por quien suspiro todos los momentos.

\section{Carta n. ${ }^{\circ} 4$}

Carta cuarta del Viajero L. R.

Santafé de Bogotá, febrero 8 de 1804

Mi suspirado amigo,

Cada día descubro nuevas riquezas en este país. Después de mi viaje a Zipaquirá he corrido toda esta gran llanura, haciendo excavaciones, y examinando sus preciosidades. El antiguo valle de Funzha, hoy Bogotá, se halla excavado en una formación secundaria, compuesta de tres lechos o capas minerales que encierran materiales útiles a los usos de la vida humana. Sobre las rocas primitivas de granito, que constituyen el núcleo de esta gran cordillera, se halla colocado el gres, de que te he hablado en mis cartas anteriores, y sirve para los edificios, no siendo otra cosa esta piedra sino un conjunto de granos cuarzosos, cimentados por la arcilla.

El gres se descubre en las montañas que rodean la explanada, y de su destrucción y aluvie (sic) se ha formado la capa de tierra vegetal que cubre toda esta llanura. En el gres se halla sobrepuesto el yeso, que se descubre y abunda en Tunjuelo, Usme, Zipaquirá, Chegua, y sobre todo al Nordeste del cerro de Tunjos cerca de Cucunubá, a una altura muy considerable. Al yeso sigue la piedra calcárea que sirve también para la arquitectura y se beneficia cerca de Monserrate y Usaquén, no encontrándose en aquellos sitios las conchas petrificadas que acompañan esta formación cerca de Tocayma y Melgar. ${ }^{12}$

[El gres contiene] camas de arcilla en algunos parajes muy bellos como son los que se encuentran en Gachancipá, Tocancipá, Chaleche, y entre Zipaquirá y Cogua. A esta formación de gres acompaña la mina de fierro obscuro (oxido de fierro amarillo) que no se explota en estos lugares, que mendigan de fuera un metal tan necesario para la agricultura, comprando a precios muy subidos el que se trae de Vizcaya, siendo abundante en Monserrate, cerca de Guatavita, Tequendama, y en otros muchos sitios del reino. También se halla con el gres el carbón de piedra que solo usan los herreros, no conociéndose

\footnotetext{
${ }^{12}$ Esta ruta fue también recorrida por Humboldt y Bonpland a su paso de Bogotá a Popayán, antes de encontrarse con Caldas al norte de Ibarra y cerca de la actual frontera entre Colombia y Ecuador. Para mayor información sobre el paso de estos viajeros por el Nuevo Reino de Granada, véase Gómez Gutiérrez (2018).
} 
aun el precio de este fósil en unos países tan abundantes de leñas. Se encuentra este carbón al sudueste de Canoas, cerca de Chipa, en la montaña aislada de Suba, junto al cerro de Tunjos. ${ }^{13}$

En el yeso se halla subordinada la capa de sal gema, que se encuentra inmediatamente bajo de aquel en las minas de Rute, ${ }^{14}$ de modo que no se puede dudar sobre la situación de este producto precioso.

Te he hablado demasiado de las abandonadas riquezas de que la naturaleza ha proveído estos lugares, que puede ser florezcan algún día, para lo que se necesitan todas las fuerzas de la opinión, hallándose estas gentes acostumbradas de largo tiempo a depender de la Europa, no necesitando sino de sus propios recursos para ser poderosos; pero la suerte de la América ha sido ser presa infeliz de los conquistadores europeos, que han establecido el despotismo en esta parte del globo. Cuando leas mis Diarios hallarás pormenores más interesantes sobre la política española con sus colonias, ${ }^{15}$ y mientras tanto sabe que te piensa tu verdadero amigo.

\section{$\operatorname{Carta} n^{\circ} 5$}

Carta quinta del Viajero L. R.

Santafé de Bogotá, febrero 19 de 1804

Mr.,

Las riquezas literarias de Santafé exceden a lo que se podía esperar de un país tan distante del centro de luces, y cuya constitución política se opone, como ya os he dicho, a los adelantamientos científicos. La biblioteca pública constará de más de veinte mil volúmenes, entre los cuales se encuentran muchas obras preciosas de la antigüedad. Los extinguidos jesuitas hicieron este admirable acopio, que los hace dignos del elogio del célebre Montesquieu, ${ }^{16}$ que hablando de estos misioneros dice que unían a la voz del Evangelio las artes que contribuyen a la felicidad temporal de los hombres.

El botánico Mutis merece la opinión en que es tenido entre los sabios de Europa. No se le puede acusar sino de ser algo misterioso, y poco accesible a los jóvenes del país, que quisieran tomar lecciones de tan gran maestro. Sin embargo, es preciso confesar que él fue el primero que comenzó, por decirlo así, a descuajar el terreno para plantar el árbol de las ciencias, que parece va a florecer en estas regiones. Mutis posee una gran librería donde se hallan las obras de los mejores naturalistas. El sabio Humboldt decía que esta colección era comparable a la de Mr. Banks, ${ }^{17}$ presidente de la Sociedad Real de Londres. Ha puesto Mutis en su casa escuela de dibujo, en que se enseña gratis $^{18}$ a los jóvenes de la ciudad. Trabaja en la flora de Bogotá, para la que ha acopiado inmensos materiales. ${ }^{19} \mathrm{Su}$ herbario se compone de más de veinte mil plantas, bastante bien conservadas. Se han ejecutado ya dos mil láminas para la Flora con una perfección inimitable.

En las religiones, ${ }^{20}$ colegios, y aun en muchas casas particulares, hay también librerías copiosas, que no se encuentran en muchos lugares cultos de Europa.

\footnotetext{
${ }^{13}$ Todos los lugares mencionados en este párrafo fueron visitados por Humboldt en 1801 .

${ }^{14}$ Así se llamaba la principal mina de sal en Zipaquirá. Por demás, Humboldt hizo el mismo comentario en sus diarios (Humboldt, [1799-1801] 1982, 60,a).

${ }^{15}$ El evidente interés que Humboldt habría mostrado a sus contertulios a su paso por la Nueva Granada, y las notas manuscritas que Caldas tuvo la oportunidad de revisar en su convivencia con el prusiano en Quito, permiten postular que el payanés se enteró de primera mano de este tipo de inclinación crítica que resultaría en al menos dos obras independientes tituladas Essai politique sur le royaume de Nouvelle-Espagne (1811) y Essai politique sur l'île de Cuba (1826).

${ }^{16}$ Charles Louis de Secondat, barón de Montesquieu (1689-1755), filósofo y ensayista francés autor de varias obras, incluyendo De l'esprit des lois (1748) con la que se enfrentó a los jesuitas, y a cuyos ataques contestó en una obra sucesiva titulada Défense de l'esprit des lois (1750).

${ }^{17}$ Sir Joseph Banks (1743-1820), naturalista y viajero británico.

${ }^{18}$ En cursivas en el original.

${ }^{19}$ La muerte nos arrebató a este sabio el 11 de diciembre de 1808. [Nota original de los editores].

${ }^{20}$ Se refiere tal vez a los seminarios y conventos.
} 
En mi última carta, que dirigí por Caracas, te hablo sobre las costumbres de estos habitantes. Verás que mi juicio conviene con el de Humboldt, que descubrió en Santafé las disposiciones más favorables al progreso de las ciencias. Si estos pueblos tuviesen un gobierno nativo que los animase; si no estuviesen sujetos a comer, vestir, y hasta pensar, si se puede decir así, por mano ajena, veríamos dentro de muy poco florecer el nuevo reino, que hasta ahora ha sido un país entregado a la voracidad de los empleados europeos.

No esperes orden en la correspondencia de un viajero, que es traído acá y allá por los diversos objetos que se le presentan, teniendo que dividir su tiempo entre la observación y los deberes cumplimentales. Por las noches nos retirarnos mi compañero y yo á poner por escrito las especies que hemos recogido en el día, no pudiendo llevar sino apuntamientos para ayudar a la memoria. ${ }^{21}$ Así es que todas las obras de los viajeros se resienten del movimiento en que están sus autores. No obstante, yo espero a mi vuelta a la Europa escribir una obra metódica ${ }^{22}$ que dedicaré a la amistad con que siempre has honrado a tu invariable amigo,

L. R.

\section{Discusión}

Se infiere del contenido de esas cinco cartas sucesivas la presencia de un extranjero europeo (eventualmente francés) de visita en el virreinato de la Nueva Granada en los primeros años del siglo XIX, que posee conocimientos científicos no desdeñables y que no está solo en sus correrías, puesto que menciona la existencia de un compañero.

La única pista acerca de su identidad son las iniciales L. R. Se ignora el nombre de la persona que lo acompaña -para referirse a él escribe simplemente "mi compañero"- así como la identidad de la persona (parece ser una sola) a quien va dirigida la correspondencia. Es curioso, entonces, que no hayan quedado registrados ni la identidad del redactor primario (L. R.), ni la de su corresponsal amigo (presunto informante de los editores, a no ser que el hipotético L. R. haya dejado -en manos también anónimas- una muestra de su archivo copiador epistolar), en tiempos en los que era usual el recurso editorial de los elogios explícitos a todo aquel que aportaba al bien del Reino.

La actitud reservada que exhibieron los editores del DPSB agudiza el misterio, pues se abstuvieron de aportar algún tipo de información adicional que permita identificar al viajero remitente. Se ignora, muy especialmente, cómo lograron conseguir acceso a unas cartas que fueron enviadas por el autor (L. R.) a un corresponsal incógnito, o si contaron con la anuencia de este viajero anónimo, o bien del receptor de las epístolas, para su reproducción en un medio de comunicación local en Santafé; aparentemente estas fueron redactadas en español, puesto que no se menciona si fueron o no traducidas de algún idioma extranjero. Finalmente, no se puede interpretar fácilmente cómo llegaron estas cartas a manos de los editores del DPSB desde las de un eventual corresponsal en Europa, puesto que en la Carta $n .{ }^{\circ} 5$ le refiere que le había dirigido su "última carta [...] por Caracas", y le describe en esta y en las anteriores con un detalle excesivo lo que era fácilmente evidente para cualquier corresponsal radicado en la Nueva Granada: esto refuerza la hipótesis de que se trata de un corresponsal europeo.

No deja de parecer sorprendente que Caldas, uno de los editores, haya publicado estas cartas sin incluir sus propios comentarios, tal y como lo hacía sistemáticamente en el $S N R G$, y como lo hizo, en particular, en el reporte sobre la geografía de las plantas que envió Humboldt a Mutis a través de sus manos en 1803, y que Caldas publicó en 10 números sucesivos del $S N R G$ entre abril 23 y junio 25 de 1809. ¿Por qué no comentar los

\footnotetext{
${ }^{21}$ Esta descripción del día a día de los viajeros corresponde exactamente a lo vivido por Caldas con Humboldt y Bonpland en Quito en el primer semestre de 1802.

${ }^{22}$ La obra metódica que Humboldt iniciaría en 1805 en París fue expuesta por Caldas en el número 24 del Semanario del Nuevo Reyno de Granada, publicado en el mes de junio de 1809. Véase Gómez Gutiérrez (2018, II, 431-438).
} 
datos y reportes de materias tan cercanas a sus propios intereses? ¿Por qué no comentar, en la Carta $n .^{\circ}$ 2, todo lo relativo al Observatorio que él mismo había descrito más de dos años antes en el SNRG (Caldas, 1808)? ¿Por qué no ahondar en la relación fitogeográfica de diferentes especies que aparece en la primera carta? En el dominio científico, solo aparece adicionalmente una nota a pie de página relacionada con el Observatorio de Filadelfia en la segunda carta, y una nota sobre la muerte de Mutis en la quinta carta.

Al margen de estos detalles ciertamente anómalos, varios aspectos que conciernen a la ausencia del registro de eventos de lo ocurrido en la Nueva Granada a comienzos del siglo XIX despiertan mayores suspicacias. Una de estas, fundamental, es que aparte de la referencia explícita de las cartas en cuestión, no ha sido posible encontrar el más mínimo registro del paso de dos viajeros como los que se referencian en dichas epístolas, para el periodo en que habrían realizado su travesía por el territorio neogranadino (i. e., a finales de 1803 y comienzos de 1804). Solo dos viajeros extranjeros podrían corresponder eventualmente a estas iniciales: Louis de Rieux, padre o hijo. Pero el padre, nacido en 1755 en Carcasona, Francia, había ya habitado en Santafé en la última década del siglo XVIII, cuando interactuó con Antonio Nariño en medio de la controversia de la publicación de la traducción de los derechos del hombre. El hijo, Luis Francisco de Rieux, nacido también en Carcasona veintiocho años después, el 15 de octubre de 1783, había sido bautizado en Facatativá el 29 de enero de 1794 cuando tenía ya 10 años cumplidos. ${ }^{23}$ En consecuencia, ninguno de los dos De Rieux podría haber iniciado la Carta $n .^{\circ} 1$, firmada el 3 de diciembre de 1803, diciendo que: "El día 20 del mes anterior entramos en la llanura de Santafé. No te puedo ponderar la sensación que me causó un golpe tan hermoso, después de haber atravesado las malezas del río Magdalena, y el resto de mal camino por tierra desde Honda hasta Facatativá, de que te hablé en mi carta anterior". Tampoco corresponde la mayoría de lo referido en las cinco cartas consecutivas a la vida y obra de los De Rieux, al dejar por fuera elementos claves de su experiencia como el de inspector de quinas del padre, y el hecho de haber ellos mismos viajado con Alexander von Humboldt y Aimé Bonpland entre abril y junio de 1801, desde Turbaco hasta Honda (Humboldt, [1799-1801] 1982, 11a).

A modo de contraste, se puede revisar esa misma visita de Humboldt y Bonpland realizada en el año 1801, la cual despertó un amplio cruce de correspondencia entre los miembros de la élite ilustrada, y de la que quedó un extenso registro histórico, incluyendo su impresión a la llegada a la llanura de Santafé en los términos expuestos en la Carta $n .^{\circ}$ 1 (Gómez Gutiérrez, 2018; Humboldt, [1799-1801] 1982, 42a).

La ausencia completa de algún tipo de registro de esta visita en 1803-1804 es irregular, puesto que el propio viajero L. R. refiere en la Carta $n .{ }^{\circ} 1$ que, él y su compañero, eran muy populares entre los ciudadanos: "A mi compañero y a mí nos rodean continuamente, queriendo imponerse de todo, de suerte que, si nos estableciésemos en este lugar, dentro de poco tiempo tendríamos tantos discípulos como se dice haber tenido Mr. Cujas". El aislamiento imperante en esos días en el territorio del Nuevo Reyno de Granada hacía efectivamente de cada visita de extranjeros un evento digno de recordación (Pérez-Mejía, 2004). De modo que no deja de parecer sorprendente que no haya quedado ni el más mínimo indicio adicional del paso de L.R. y su compañero por territorio neogranadino.

Además de lo anterior, existen varios aspectos contenidos dentro de las cartas que, reunidos en su conjunto, determinan que deba colocarse en tela de juicio la propia existencia del viajero L. R. y, por supuesto, la veracidad al pie de la letra de lo que se registra en ellas.

\footnotetext{
${ }^{23}$ Gracias al hallazgo de la partida de bautismo de este joven francés en Facatativá por parte de la historiadora María Clara Guillén de Iriarte (comunicación personal), se puede precisar que el hijo de Louis de Rieux (1755-1840) fue bautizado en la iglesia sabanera el 29 de enero de 1794, con Antonio Nariño como padrino sustituto en ausencia de Francisco Miranda y Tobar, venezolano, en honor a quien fue bautizado Luis Francisco de Rieux. La partida indica de manera explícita que el bautizado tenía en ese momento "9 años cumplidos". Véase Gómez Gutiérrez (2018, I, 1, 270).
} 
Iniciemos por el relato de los instrumentos con que cuenta el Observatorio astronómico: al describirlos, L. R. menciona la existencia del "péndulo de Graham, que trajeron a Quito nuestros académicos" (Carta $n .{ }^{\circ} 2$, de diciembre de 1803), como uno de los aparatos que integran la dotación del Observatorio. Sin embargo, dicho reloj solo vino a ser parte del instrumental de esta institución en diciembre de 1805, cuando Caldas arribó con él a Santafé después de haberlo adquirido en Quito. De hecho, el reporte de Caldas sobre la propiedad sucesiva de este instrumento fue anotada por él mismo a pie de página en el $S N R G$ en su "Descripción del Observatorio" en febrero de 1808: "M. de la Condamine vendió este péndulo al Reverendo Padre [fray Domingo] Terol, dominicano en Quito, [Doctor en la Real Universidad y Rector del Colegio de San Fernando] y profundo en el arte de la relojería. A su muerte lo compró esa Audiencia para arreglar sus horas; pero poco propio para este destino, pasó a manos de don N. Proaño, hábil relojero [en Quito] y de cuyo poder lo saqué para el Observatorio" (Caldas, 1808).

¿Cómo es posible, entonces, que un visitante en Santafé y en particular a su recién construido Observatorio, conozca de la existencia de un instrumento que solo llegará a ese sitio dos años después de su visita?

Igualmente inconsistente resulta el comentario relacionado con el herbario de la Expedición que, por lo visto, habría observado L. R. con lujo de detalle: "Su herbario se compone de más de veinte mil plantas, bastante bien conservadas. Se han ejecutado ya dos mil láminas para la Flora con una perfección inimitable" (Carta . $^{\circ} 5$ ). Estos comentarios precisos a la obra de José Celestino Mutis realizados por un viajero extranjero en 1803, suponen un encuentro personal del que no existe la menor traza en los diarios ni en la correspondencia del gaditano.

Hay varias anomalías adicionales que merecen también citarse, y que tienen que ver con su repetida mención de Alexander von Humboldt (Cartas $n{ }^{o s} 2$ y 5 ).

Primeramente, hay tres alusiones al prusiano en las cartas: la primera comentando la Memoria que redactó sobre las salinas de Zipaquirá. Bien puede argumentarse que L. R. haya tenido acceso a esta Memoria estando en Santafé, pues al menos dos copias de este manuscrito quedaron en poder de Mutis (como se puede comprobar hoy en el Fondo José Celestino Mutis del Real Jardín Botánico de Madrid). Las dos restantes alusiones a Humboldt tienen que ver con el comentario que este hizo de la extensa biblioteca de Mutis y con la opinión acerca de las buenas disposiciones que poseían los santafereños para el progreso de las ciencias. Pero ¿cómo hizo para enterarse L. R. sobre estos dos comentarios en un año tan temprano como 1803 cuando Humboldt en esos momentos se encontraba viajando entre el Perú y México a través del Océano Pacífico, y la inmensa mayoría de sus experiencias de viaje aun se hallaban consignadas en los diarios personales que portaba celosamente?

Por otra parte, y suponiendo que L. R. no hubiese fallecido en su periplo por América o en su viaje de regreso a Europa, es poco probable que, de haber sobrevivido y retornado a su patria, este viajero hipotéticamente francés no hubiese entrado en contacto con Humboldt, quien se radicó en París entre 1804 y 1827. Es altamente probable que Humboldt lo hubiera citado en algún aparte de su voluminosa obra, pero, hasta la fecha, no se ha encontrado ninguna evidencia de contactos del prusiano con este viajero que prácticamente había seguido sus pasos por Venezuela, Cartagena, el río Magdalena y el altiplano cundinamarqués (Gómez Gutiérrez, 2018).

Al concentrar la atención propiamente en la redacción y estilo de las cartas, resulta un tanto extraña la forma poco constante como L. R. se dirige hacia su corresponsal, abriendo la primera carta con un "amigo", y cerrándola con "tu afectísimo amigo"; luego, pasó a abrir la segunda carta con "mi pensado amigo", y retornó en la tercera a una discreta apertura dirigida a su "amigo", que cerró unas líneas después con una más que amistosa declaración que examinaremos en el siguiente párrafo. A estas alturas, se lanzó a abrir la cuarta carta con "mi suspirado amigo" y a cerrarla con un "sabe que te piensa tu verdadero amigo", para llegar a la última apertura (aparentemente fatigada) con un frío y abreviado 
"Mr", prometiéndole, sin embargo, que, no obstante, esperaba a su vuelta a la Europa escribir una obra metódica que dedicaría a la amistad con que siempre había honrado a su "invariable amigo".

Si bien, en general, parece existir una simple relación amistosa entre el emisor y el receptor, característica de dos varones que se profesan entre sí un mutuo aprecio, en la continuación de la Carta $n .^{\circ} 3$, en su último párrafo, surgen dos apartes que evidencian un vínculo más intenso, más afectivo, más íntimo: Expresiones como “...las grandes ventajas que aquí se gozan, y que quisiera dividir contigo...", o bien "creo que por estas bellas circunstancias viviría contento en este país ameno; pero la mitad de mi ser está lejos de mí, y no puedo vivir gustoso sin mi caro amigo por quien suspiro todos los momentos", no pueden pasar inadvertidas, aunque este tipo de expresiones románticas hayan sido relativamente usuales en el paso del siglo XVIII al siglo XIX. Es extraño que esta Carta $n .^{\circ}$ 3, que se inicia con un sencillo "amigo", haya terminado con esos fogosos apartes que no fueron sistemáticos, y que parecían estar fuera del tono del contenido general de las cinco epístolas. Es como si el verdadero autor de estas relaciones, relativamente incoherentes, hubiera aprovechado esta tribuna para revelar de manera anónima sus más profundos sentimientos, o los más profundos sentimientos de quien estaba suplantando.

Estos altibajos con sus corresponsales fueron, por otra parte, característicos en el propio Caldas como lo refirió el Padre Enrique Pérez Arbeláez en su artículo titulado "La ciencia y la historia", en el que concluyó que "el Caldas todo ternuras, todo sahumerios, todo néctar, cuando se le truncaba la ilusión o se le frustraban las esperanzas, o se le incumplían promesas ciertas o por él imaginadas, se volvía de vino en vinagre, tanto más ácido cuanto que su talento le descubría mejor el lado flaco de sus ídolos del día anterior" (Pérez Arbeláez, [1959] 2018).

Aparte de lo anterior, un aspecto notable, este sí perfectamente recurrente en el conjunto las cinco cartas, es el notable parecido de la narración del viaje de "L. R." (que resulta ya apropiado registrar entre comillas) con el que Humboldt realizó con Bonpland dos años y medio antes en su hipotético paso por la Nueva Granada. Ambos, "L. R." y Humboldt, tienen un compañero de viaje, cargan numerosos diarios, ambos han visitado el río Orinoco; son deslumbrados por la belleza de la Sabana de Bogotá, visitan las salinas de Zipaquirá (originando prácticamente idénticos comentarios), reflejan poseer conocimientos en botánica, geología, astronomía e industria minera; ambos son receptores de numerosos obsequios, son dados a ser críticos del gobierno colonial imperante, son proclives a mantener intensas relaciones masculinas, y planean, a su retorno a Europa, escribir una obra "metódica" que dé cuenta de todas sus observaciones y experiencias.

Llegados a este punto, frente a las inconsistencias anotadas y al asombroso parecido entre la narración de "L. R." y la de Humboldt, nos parece ya conveniente enunciar la hipótesis formal de que el autor de las cartas que nos ocupan no es otro que el propio Francisco José de Caldas. En consecuencia, se plantea que Caldas se permitió con facilidad - dada su condición de coeditor del DPSB - incluir esta ficción literaria en estas páginas teniendo como inspiración la visita de Humboldt y Bonpland, con quienes había convivido cerca de cinco meses en Quito y de quienes tuvo referencias múltiples a su paso por Cartagena, Santafé y Popayán. Se puede descartar al segundo editor del DPSB -José Joaquín Camacho- como autor primario de estas misivas pseudónimas, pues a pesar de haber realizado estudios en derecho y poseer una mente sagaz y hábil políticamente, carecía de ciertos conocimientos científicos y, lo que es más importante, no había tenido la experiencia de trabajar al lado de Humboldt por varios meses, de sostener correspondencia con él, ni de haber examinado sus diarios. Sin embargo, es claro que la inclusión de las cartas que postulamos hoy como caldasianas, debió contar con la anuencia de Camacho.

No fue esta la primera vez que Caldas anonimizó sus comunicaciones. Un importante antecedente es su artículo publicado en 1801, en los números 23-25 del Correo Curioso, bajo el título "Observaciones sobre la verdadera altura del cerro de Guadalupe que domina esta ciudad", en donde se refiere a las mediciones halladas "en un manuscrito intitulado Relación de un viaje de Santafé de Bogotá a Popayán hecho en 1796 por N." (Caldas, 
[1801] 1966). "N" es, naturalmente, Caldas. Así lo revela él mismo en el cierre de la comunicación con un "[...] el motivo que me mueve a remitirles este trozo final de mi Relación de viaje, es por provocar a los físicos de esa capital a que repitan las observaciones del barómetro sobre Guadalupe, y también en Monserrate, a donde no pude subir [...]".

Eduardo Posada interpretó el hecho con la siguiente nota a pie de página: "El autor es, según se ve luego, el mismo Caldas, que ocultó al principio modestamente su nombre". Sin embargo, los motivos de Caldas parecían ser más complejos que una simple modestia. Así lo confesó a Santiago Arroyo en carta firmada en Popayán en junio 20 de 1801: "Ya usted, en compañía de mis otros amigos, me quiere echar al público: yo aprecio su afecto y la estimación que hacen de mis cosas; pero no era tiempo de quitarme la máscara y aparecer en el mundo literario. Mejor habría sido mantenerme algunos años más a la sombra de un nombre griego o de unas iniciales, hasta haberme formado y representar en el país de las letras mi papel con alguna dignidad. Usted debió oponerse a esta presentación temeraria con todas sus fuerzas; usted, que acaba de pasar por el mismo camino, que se ha puesto a cubierto bajo la voz Polifilo, debía haber apetecido y procurándome la misma satisfacción; ya no podré, como usted, oír la censura de mis producciones en mi presencia, censuras tanto más apreciables cuanto las dictan la razón y la verdad, lejos de toda preocupación, respeto y amor hacia su autor. Si acaso no se ha impreso todavía, es necesario me evite usted mil cuidados y me dé la satisfacción de probar por esta y por otras piezas que tengo en bosquejo, el juicio que forma el público de un nuevo ciudadano que de repente aparece en el mundo literario. No estoy contento con que se dé mi nombre, y mucho menos con que se me elogie. Todos los hombres somos orgullosos y vemos con repugnancia, y quizá con pena, los elogios que se prodigan a otro. Es verdad que este vicio es propio de las almas bajas y pequeñas; ¿pero el común de los hombres no la tiene de este temple? Las almas grandes, las almas generosas son pocas, porque lo bueno siempre es raro; en fin, temblando aguardo los correos siguientes y las lluvias de críticas, murmuraciones y censuras; yo estoy bien seguro que no me tomaré el trabajo de responder; pero vamos a otra cosa" (Caldas, [1801] 1978).

El eventual seudónimo "L. R." de 1810 no parece surgir tampoco de la modestia de Caldas. Así, quedan al menos dos preguntas ineludibles en este punto: ¿Cuáles fueron los motivos que condujeron a Caldas a permitirse la libertad de crear un viajero ficticio por el territorio neogranadino, una especie de pseudo-Humboldt, cuyas apreciaciones sobre la región, sus ciudadanos y su gobierno quedaron consignadas en unas supuestas cartas que escribió a un amigo? ¿Por qué incluirlas en un medio escrito cuya circulación abarcaba, en principio, todas las provincias de la Nueva Granada?

Proponemos una sola respuesta: Caldas lo hizo en función de un necesario proselitismo político en el segundo semestre de 1810. Debe recordarse que los trastornos existentes en España ocasionados por la invasión de Napoleón Bonaparte originaron, prácticamente en toda la América española, una fuerte reacción de rechazo hacia los representantes del gobierno peninsular lo que condujo al establecimiento de gobiernos locales conformados por las élites criollas, no solamente en las capitales de los virreinatos existentes, sino también en las capitales de provincias e incluso en poblaciones intermedias que se veían así mismas con el legítimo derecho a hacerlo. El Nuevo Reyno de Granada no fue la excepción (Liévano, 2002). De modo que la Junta Suprema establecida en Santafé debía justificar no solo el advenimiento de un gobierno más idóneo y capaz: debía además controlar el surgimiento de una amplia diversidad de Juntas surgidas en numerosos sitios de virreinato pues la mayoría de ellas se negaban a plegarse a su poder e influencia (Gutiérrez Ardila, 2010).

Y es allí donde los órganos de vocería de la Junta Suprema entran en juego, haciendo un llamado a las provincias a mantener la unión y dar por hecho obvio que es Santafé, por su tamaño, por su prestigio y por la excelencia de sus gentes, la que debe apadrinar el proceso para la elección de la mejor forma de gobierno. El suplemento del No. 1 del DPSB lo estipula claramente: "Las provincias del reino no deben tomar partido por sí solas en la 
presente crisis [...]. Somos un cuerpo de nación; los fondos, los intereses son comunes; unas mismas las leyes que nos gobiernan [...]. Sería un procedimiento el más impolítico romper estos vínculos sagrados, separarnos cuando nos debemos unir más estrechamente", y más adelante: "En la Capital del Reino se verá cómo piensan las provincias y de acuerdo con sus representantes $[\ldots]$ se resolverá la forma de gobierno que más nos convenga adoptar [...] la Capital no trata de subyugar los pueblos, sino de reunirlos para establecer la buena armonía" (Caldas \& Camacho, 1810).

De modo que Caldas recurre a la hábil licencia de crear un personaje que, a través de sus cartas, pone en evidencia las fallas y el desgano de la administración colonial, exhibe una imagen más favorable de Santafé y de sus habitantes, y resalta, de una manera aparentemente objetiva como puede serlo la visión de un viajero extranjero, la riqueza y potencialidad que tiene el territorio como nación independiente.

En cuanto al primer propósito, se pueden evocar los siguientes apartes: "bajo otro gobierno [los dos ríos que atraviesan la ciudad] podrían contribuir más al placer y a la salubridad"; "el Gobierno favorece poco las ciencias (comentario un tanto inapropiado para haber sido redactado en 1803, ya que en esos días estaba plenamente vigente la Expedición Botánica), y mucho menos las artes, que perjudicarían al sistema colonial" (Carta n. ${ }^{\circ}$ 1); "El gobierno debe interesarse en adelantar y perfeccionar la explotación y fábrica de [la sal]" (Carta.$^{\circ} 3$ ); "[la] constitución política se opone [...] a los adelantamientos científicos"; "Si estos pueblos tuviesen un gobierno nativo que los animase; si no estuviesen sujetos a comer, vestir, y hasta pensar, si se puede decir así, por mano ajena, veríamos dentro de muy poco florecer el nuevo reino, que hasta ahora ha sido un país entregado a la voracidad de los empleados europeos" (Carta n..$^{\circ}$ 5). Esta última predicción es claramente anacrónica, a menos que estemos frente a un excepcional don de clarividencia en "L. R." siete años antes de los sucesos del 20 de julio de 1810.

En cuanto a poner en evidencia el talento de los habitantes de Santafé se pueden resaltar las siguientes líneas: "Los ciudadanos están dotados de genio, y se observa en casi todos un deseo insaciable de saber [...]. Hay hombres bastante instruidos, reina en todos un gusto delicado, expresión fina, y si hubiera cultivo podría ser esto un París (Carta $\left.n .^{\circ} 1\right)$; "No carece esta capital de hombres capaces de hacer [delicadas observaciones astronómicas $\left.{ }^{24}\right]$ " (Carta n. ${ }^{\circ}$ ); "mi juicio conviene con el de Humboldt, que descubrió en Santafé las disposiciones más favorables al progreso de las ciencias" (Carta $n .^{\circ} 5$ ). No hay que olvidar, sin embargo, que Humboldt usualmente exaltaba en público a sus anfitriones, pero en sus diarios íntimos (que redactó en alemán), al referirse a los habitantes de la Nueva Granada, escribió que estaba en "un país en donde nadie se toma el trabajo de formarse ideas claras sobre nada" y en el que "no se razona" (Humboldt, [1799-1801] $1982,58$ a y $112 a)$.

Sobre la riqueza y potencialidad de la nación: "te admirarías si te hallaras presente en los esplendidos (sic) convites con que se nos obsequia y en que hemos visto muchas composiciones gastronómicas que lograrían aprecio en la culta Europa" (continuación de la Carta . $^{\circ} 3$ ); "Cada día descubro nuevas riquezas en este país" [...]. Te he hablado demasiado de las abandonadas riquezas de que la naturaleza ha proveído estos lugares, que puede ser florezcan algún día, para lo que se necesitan todas las fuerzas de la opinión, hallándose estas gentes acostumbradas de largo tiempo a depender de la Europa, no necesitando sino de sus propios recursos para ser poderosos; pero la suerte de la América ha sido ser presa infeliz de los conquistadores europeos, que han establecido el despotismo en esta parte del globo" (Carta n. 4); "Las riquezas literarias de Santafé exceden a lo que se podía esperar de un país tan distante del centro de luces", y "En las religiones, colegios, y aun en muchas casas particulares, hay también librerías copiosas, que no se encuentran en muchos lugares cultos de Europa" (Carta $n .^{\circ} 5$ ).

${ }^{24}$ Una evidente auto referencia de Caldas. Véase Portilla (2016). 
Tampoco se puede descartar que algunos de los comentarios, más allá de aludir al deficiente gobierno colonial que se acababa de sustituir, aplicaran también como recomendaciones explícitas al nuevo gobierno, tales como hacer efectivas las recomendaciones de Humboldt sobre la manera de sacar mejor provecho de la producción en las salinas de Zipaquirá.

Como se ve, no hace falta escarbar demasiado para evidenciar una clara y manifiesta intención política en la redacción de esas cinco cartas. Caldas, paradójicamente, habría procurado cubrir sus huellas colocando ciertos poblados con ortografía incorrecta, haciendo gala de una prosa un tanto etérea en algunos apartes, y utilizando información inexacta como la altura del Salto de Tequendama, o registros astronómicos erróneos como el que se refirió al tránsito del planeta Venus. Pero, inadvertidamente, dejó huellas inequívocas de una identidad neogranadina no francesa del hipotético "L. R.", representadas por errores ortográficos de apellidos franceses como Lalande (no "La Land"), entre otras trazas.

Por encima de estos eventuales errores voluntarios, hay ciertos aspectos sutiles en los que la personalidad de Caldas aflora de forma inevitable. Ejemplo de ello son el que: a- El autor de las cartas no posea un concepto positivo de los estudios de derecho. Al hablar de las enseñanzas que impartió el jurisconsulto Cujas se refiere a ellas en términos desdeñosos, pues para él son desagradables y poco útiles. Caldas, que recibió el título de bachiller en derecho, manifestó su aversión a esa práctica. En la primera carta que le escribió a Mutis dirá "me pusieron a Vinio ${ }^{25}$ en las manos; pero yo no había nacido para jurisconsulto. A pesar de los castigos, reconvenciones y ejemplos, yo no pude tomar gusto a las leyes ni a Justiniano, y perdí los tres años más preciosos de mi vida" (Caldas, [1801] 1978, carta 41). Así mismo, en una misiva dirigida a Santiago Arroyo anotó: "No repruebo el estudio de la jurisprudencia: conozco su necesidad y sus ventajas; pero para cuatro procesos en que se disputa una cuadra de terreno, un derecho ridículo, cuatro matas y otras tantas frioleras, tiene usted un cúmulo de conocimientos superior a cuantos asuntos forenses se pueden presentar en nuestros países. Si, deje usted ya a esos jurisconsultos y vamos a hacer algo que pueda sernos útil y haga honor a nuestra patria" (Caldas, [1801] 1978, carta 40); b- Si bien "L.R." reconoce la estatura científica de Mutis, refiere que es "algo misterioso, y poco accesible a los jóvenes del país, que quisieran tomar lecciones de tan gran maestro", comentario parecido al que hace Caldas cuando describe el carácter de Mutis al secretario del virrey Amar y Borbón (Caldas, [1809] 1978, carta 132).

Caldas, al final de la $\operatorname{Carta} n^{\circ} 5$, parece caer en cuenta de las inconsistencias y el desorden de sus reflexiones e intenta subsanarlas con una justificación plausible, de manera que escribe en el último párrafo: "No esperes orden en la correspondencia de un viajero, que es traído acá y allá por los diversos objetos que se le presentan".

Para terminar esta sección expondremos un aspecto que, aunque hemos de reconocer, es netamente circunstancial, puede apoyar la tesis de que Caldas es el redactor de las cartas que nos ocupan. Ya hemos comentado la fogosidad del último párrafo en la continuación de la Carta $n^{\circ} 3$ aparecida en el No. 19 del DPSB, con el que "L. R." se despide de su amigo, confidente, y ahora, de improviso, depositario de sus apasionados anhelos. Pues bien, la primera parte de aquella carta apareció en el número anterior, en el No. 18, en el que está incluida, entre otras secciones, una nota titulada "Quito, septiembre 20 de 1810", en la que se comenta que el Comisionado Regio Carlos Montúfar fue recibido allí en medio de un "concurso inmenso" y en el que sus habitantes "corrían en tropa, lloraban todos de placer y lo victoreaban (sic) llamándole su Libertador" (esta última palabra en itálica en el original). Este Carlos Montúfar no es otro que Carlos de Montúfar y LarreaZurbano (1780-1816), el hijo de Juan Pío de Montúfar y Larrea (1758-1819), II marqués de Selva Alegre y, como tal, un digno exponente de lo más granado de la aristocracia quiteña. Como es sabido, Carlos Montúfar fue el joven quiteño a quien Humboldt decidió llevar consigo en el resto de su viaje por América en lugar de Caldas, lo que originó en este

${ }^{25}$ Se refiere al jurisconsulto holandés Arnoldo Vinnio (1588-1657), autor de un importante tratado de derecho. 
una enorme frustración y ocasionó el enfriamiento y distanciamiento en sus relaciones, pues Humboldt argumentó, frente a la insistencia de Caldas de acompañarlo, que había decidido viajar solo, lo que a la postre resultó siendo una mentira. Con o sin razones, el caso es que Caldas atribuyó su rechazo y la preferencia por Montúfar, ese "joven currutaco, ignorante y disipado" (Caldas, [1802] 1978, carta 66), al surgimiento de una relación amorosa entre ambos, lo que Caldas matizó escribiendo a Mutis y sus amigos íntimos de que Humboldt tenía un "secreto abominable" y "que los hombres más grandes tienen debilidades" (Caldas, [1802] 1978, carta 66).

De modo que para finales de octubre de 1810, en medio de los trastornos políticos que afloraban por todas partes, reaparecía en Quito Carlos Montúfar, el "adonis" de Humboldt (Caldas, [1802] 1978, carta 68), recibido ahora como un héroe, ovacionado por muchedumbres con lágrimas en los ojos y aclamado nada menos que como "Libertador". Hemos de suponer que la noticia no debió caerle en gracia a Caldas.

No sería excesivo entonces conjeturar que el payanés, frente a la novedad informativa que le despertaba el amargo recuerdo experimentado ocho años antes, no pudo evitar permitirse cierta libertad literaria y puso a redactar a su personaje, a su avatar, un párrafo explícito en el que se sugería, de repente y sin previo aviso, la tendencia de "L. R." hacia una relación excesivamente íntima entre dos hombres, aún para los estándares de la época. Un gusto semejante al que había exhibido Humboldt en su paso por América (Pérez Arbeláez, [1959] 2018). ¿Qué ganaba con esto Caldas? Poca cosa. Pero no puede descartarse que la redacción de las cartas en cuestión no solo estaba dirigida a satisfacer el objetivo principal de su proselitismo político, tal y como se argumentó ya, sino que pudieron haber servido al improvisado autor sucedáneo para comunicar entre líneas a sus amigos más cercanos un hecho que habrían ya comentado años atrás: pudo haberse tratado, en síntesis, de una caricaturización.

La presente reflexión muestra que los editores del DPSB gozaban de una amplia libertad de acción, no solo para incluir las notas que pensaban motu-proprio que serían del interés legítimo de la población, sino para disfrutar de una cierta licencia individual, y muy subjetiva, como la que acabamos de postular.

En esos mismos días, sin embargo, hubo un llamado de atención para los editores, pues el número 24, que debía emitirse el martes 13 de noviembre, solo fue publicado el viernes 16 de esa misma semana, y en su parte final se incluía una resolución de la Junta Suprema sobre la continuación del $D P S B$, pues a través de un mandato, se había suspendido la emisión correspondiente al día martes. En dicha resolución se informaba que el miércoles 14 la Junta Suprema abordó el asunto de la queja proferida por algunas provincias contra el $D P S B$ en el sentido de este fomentaba la desunión entre ellas. Como el interés de la Junta era justamente lo contrario, escuchó la versión de José Joaquín Camacho que, como hemos dicho, era vocal de esa Junta. Al final, ésta reconoció que, aunque el DPSB no tenía un rol de carácter "ministerial, nada podían perjudicar ni sus opiniones ni sus hechos aun cuando en alguna cosa menos esencial fuesen inexactos, se previene a dichos autores que en lo sucesivo pusiesen la más escrupulosa diligencia para evitar todo motivo de censura".

En consecuencia, el DPSB podía continuar "en la misma calidad de privado o particular, en lo que expresamente no se advierta ser de otra naturaleza; y sin que por esto padezca la menor nota la opinión de sus autores, cuyas intenciones sanas y juiciosas son bien conocidas al Gobierno y no se han dirigido a otra cosa que al servicio de la Patria".

Lamentablemente la resolución no ahonda en detalles de cuales fueron aquellos contenidos dentro de las hojas del $D P S B$ que ocasionaron que varias provincias expusieran su descontento frente la Junta Suprema.

\section{Conclusiones}

En el presente artículo se han presentado varias consideraciones que permiten inferir que las cinco cartas aparecidas en el DPSB redactadas por un viajero de nombre "L. R." son en realidad de autoría de Francisco José de Caldas, uno de los dos editores del diario. Hemos 
hecho la sugerencia de que "L. R." y su compañero están inspirados en dos personajes reales, Humboldt y Bonpland, quienes realizaron un periplo virtualmente idéntico al que se describe en las cartas. Caldas no tuvo mayor dificultad en la creación de "L. R.", pues no solo conoció, trabajó y convivió con Humboldt por varios meses, sino que además tuvo acceso a sus diarios y mantuvo correspondencia con él.

La intencionalidad en la creación del personaje y de sus opiniones manifestadas en las cartas, tiene el propósito de mostrar una imagen favorable de Santafé de Bogotá y de sus habitantes. Así lo expresó el editor al presentar la primera de estas cartas para: "conocer en ellas las ventajas que reúne la Capital de Santafé", en un periodo de incertidumbre política que amenazaba con poner en peligro el predominio de la capital y la unidad de la Nueva Granada. En el mismo sentido, se incluyeron opiniones tendientes a resaltar la potencialidad de la nación y sus habitantes.

Lo que se tiene entonces aquí es una estratagema consistente en ventilar unas impresiones favorables consignadas por un viajero europeo a su paso por un lugar que, a la vuelta de los años, se vería inmerso en una revolución, de modo que con ella se alentaba la confianza y la seguridad entre pobladores vacilantes e indecisos en su nueva condición de miembros de un Estado que acababa de conseguir su autonomía, considerando que se tiende a otorgar mayor peso y credibilidad a las opiniones de un forastero ilustrado.

Creemos entonces reunir las suficientes evidencias como para: 1- Poner en tela de juicio la autoría y veracidad de los contenidos de las cinco cartas en mención, y 2- Proponer que Caldas, en un arranque literario, y exaltado por los recientes triunfos de su partido revolucionario el 20 de julio de 1810 , habría aprovechado la tribuna del DPSB para hacer proselitismo político y, a la vez, posicionarse como el viajero europeizante que sintió nunca haber llegado a ser plenamente, liberando entre líneas otras angustias personales.

\section{Contribución de los autores}

AGG y JGP contribuyeron por igual en la conformación de todas las secciones del presente artículo. AGG transcribió las cinco cartas a partir de la publicación original de 1810.

\section{Conflicto de intereses}

Los autores no presentan ningún conflicto de intereses.

\section{Agradecimientos}

Los autores agradecen la lectura crítica y comentarios al texto preliminar del historiador Daniel Gutiérrez Ardila, así como los agudos comentarios y sugerencias de dos evaluadores anónimos en el curso del proceso editorial de la Revista de la Academia Colombiana de Ciencias Exactas, Físicas y Naturales.

\section{Referencias}

Bell, W. J. Jr. (1964). Astronomical Observatories of the American Philosophical Society, 17691843, Proceedings of the American Philosophical Society. 108 (1): 7-14.

Caldas, F. J. ([1801] 1966). Observaciones sobre la verdadera altura del cerro de Guadalupe que domina esta ciudad, Obras completas de Francisco José de Caldas, Bogotá: Universidad Nacional de Colombia, pp. 365-374.

Caldas, F. J. (1808). Descripción del Observatorio Astronómico de Santafé de Bogotá, situado en el jardín de la Real Expedición Botánica. Semanario del Nuevo Reyno de Granada. 7: 56-58.

Caldas, F. J. \& Camacho, J. J. (1810). Suplemento al Diario Político. Reflexiones sobre el modo con que se deben conducir las Provincias del Reyno en las actuales circunstancias, Diario Político de Santafé de Bogotá, [sin paginación].

Caldas, F. J. ([1788-1816] 1978). Cartas de Caldas, Bogotá: Academia Colombiana de Ciencias Exactas, Físicas y Naturales.

Caldas, F. J. (1810). Primera carta, firmada en Santafé de Bogotá en diciembre 3 de 1803 (DPSB16, octubre 16 de 1810, pp. 63-64): https://babel.banrepcultural.org/digital/collection/ p17054coll26/id/1409 
Caldas, F. J. (1810). Segunda carta, firmada en Santafé de Bogotá en diciembre 19 de 1803 (DPSB17 , octubre 19 de 1810, pp. 67-68): https://babel.banrepcultural.org/digital/collection/ p17054coll26/id/1410

Caldas, F. J. (1810). Tercera carta, firmada en Zipaquirá en enero 3 de 1804 (DPSB-18, octubre 23 de 1810, pp. 70-71): https://babel.banrepcultural.org/digital/collection/p17054coll26/id/1412

Caldas, F. J. (1810). Tercera carta (continuación) (DPSB-19, octubre 26 de 1810, p. 74): https:// babel.banrepcultural.org/digital/collection/p17054coll26/id/1413

Caldas, F. J. (1810). Cuarta carta, firmada en Santafé de Bogotá en febrero 8 de 1804 (DPSB21, noviembre 2 de 1810, pp. 83-84): https://babel.banrepcultural.org/digital/collection/ p17054coll26/id/1415

Caldas, F. J. (1810). Quinta carta, firmada en Santafé de Bogotá en febrero 19 de 1804 (DPSB27, noviembre 27 de 1810, pp 107-108): https://babel.banrepcultural.org/digital/collection/ p17054coll26/id/1421

Campos y Fernández de Sevilla, F. J. (2011). El P. Diego Padilla y el “Aviso al Público”, Instituto escurialense de investigaciones históricas y artísticas, Publidivisa, Sevilla.

Del Molino, R. (2017). Anticomanía cundinamarquesa. Referentes culturales y políticos grecorromanos presentes en la segunda mitad del siglo XVIII y en las primeras décadas del XIX en territorio cundinamarqués. En Taborda, I.M., Bonnett, D. (compiladores), Cundinamarca. Particularidades histórico-políticas de su formación, Escuela Superior de Administración Pública, Bogotá.

Gómez Gutiérrez, A. (2018). Humboldtiana neogranadina, 6 tomos, Editorial Pontificia Universidad Javeriana : CESA : Universidad de los Andes : Universidad EAFIT : Universidad del Rosario : Universidad Externado de Colombia, Bogotá.

Gutiérrez Ardila, D. (2010). Un Nuevo Reino. Geografía política, pactismo y diplomacia durante el interregno en Nueva Granada (1808-1816), Universidad Externado de Colombia, Bogotá.

Hernández de Alba, G. \& Carrasquilla, J. (1977). Historia de la Biblioteca Nacional de Colombia, Instituto Caro y Cuervo, Bogotá.

Humboldt, A. ([1799-1801] 1982). Alexander von Humboldt en Colombia. Extractos de sus diarios, Academia Colombiana de Ciencias Exactas, Físicas y Naturales - Academia de Ciencias de la República Democrática Alemana / Publicismo y Ediciones, Bogotá.

Ibañez, P. M. ([1893] 1951). Crónicas de Bogotá, Tomo 2, Biblioteca Popular de Cultura Colombiana, Bogotá.

Liévano, I. (2002). Los grandes conflictos sociales y económicos de nuestra historia, Intermedio, Bogotá

Mantilla, I., Ochoa, F. \& Martínez, R. (2016). Consideraciones históricas y físicas sobre la altura del salto del Tequendama con los datos de Humboldt, Revista de la Academia Colombiana de Ciencias Exactas, Físicas y Naturales. 40 (157): 580-584.

Martínez Delgado, L. \& Ortiz, S. E. (1960). El periodismo en la Nueva Granada. 1810-1811. Academia Colombiana de Historia, Bogotá.

Martínez Delgado, L. \& Ortiz, S. E. ([1960] 2018). Francisco José de Caldas, Periodista, Revista de la Academia Colombiana de Ciencias Exactas, Físicas y Naturales. 42 (supl.): 158-163.

Pérez Arbeláez, E. ([1959] 2018). La ciencia y la historia. El caso de Caldas-Humboldt - No hubo tal adonis, Revista de la Academia Colombiana de Ciencias Exactas, Físicas y Naturales. 42 (supl.): 138-141.

Pérez-Mejía, A. (2004). A geography of hard times: narratives about travel to South America, 17801849, State University of New York Press, Albany.

Portilla, J. G. (2017). Caldas y el gran cometa de 1807, Revista de la Academia Colombiana de Ciencias Exactas, Físicas y Naturales. 41 (159): 244-252.

Rojas, J. A. (2013). Doscientos años de un periódico no tan feliz, Campos en Ciencias Sociales, Comunidad, Acción y Comunicación, Vol. 1, No. 2, Universidad Santo Tomás, Bogotá.

Tisnés, R. M. (1956). Capítulos de historia zipaquireña (1480-1830), Vol. 1, Academia Colombiana de Historia, Bogotá. 